\title{
Identificação e Delimitação de Áreas Prioritárias para Controle da Leptospirose no Município de São \\ Paulo
}

Pedro José Vilaça, José Olímpio Moura de Albuquerque, Maria das Graças Soares dos Santos, Paula Regina Glasser, Ludvig Genehr, Cleir Aparecido Santana, Andrea De Meo Bancher

Coordenação de Vigilância em Saúde. Secretaria Municipal de Saúde de São Paulo.

Endereço: Rua Santa Isabel, 181, $6^{\circ}$ andar, Vila Buarque, CEP 01221-010, São Paulo, SP.

E-mail: pvilaça@prefeitura.sp.gov.br

\section{INTRODUÇÃO}

No município de São Paulo a Leptospirose tornou-se uma doença endêmica há mais de 20 anos, sendo que no período de 1998 a 2006 foram notificados, segundo o banco de dados do Sistema de Informação de Agravos de Notificação (SINAN), um total de 2.958 casos que resultaram em 413 óbitos (letalidade de 13,9). Somente em 
2006 foram notificados 364 casos e 63 óbitos, o que se traduziu num aumento da letalidade para 17,o. A média brasileira de letalidade por Leptospirose é de 10;

- Com quase $4.000 \mathrm{Km}$ de córregos, uma população superior a 11 milhões de pessoas, mais de 3 milhões de domicílios, muitos erguidos em áreas irregulares e de precárias condições higiênico-sanitárias, o município de São Paulo não possuía ferramentas que norteassem ou delimitassem espacialmente as áreas de maior risco para ocorrência de Leptospirose. Ademais, não havia um conhecimento da distribuição espacial dos casos e de sua relação com a malha de córregos do município.

OBJETIVO

Identificar áreas prioritárias para controle de leptospirose exequíveis para intervenção pelas equipes existentes.

\section{METODOLOGIA}

Utilizaram-se ferramentas de geoprocessamento e análise espacial para a seleção das áreas.

\section{RESULTADOS}

A padronização manual de endereços permitiu a localização de 2.202 casos de Leptospirose que correspondem a 81,95 dos casos ocorridos no período de 1998 a 2006 no município de São Paulo. Estes casos constituíram o universo das análises realizadas.

Aplicando-se a técnica de análise espacial conhecida como Estimador de Densidade de Kernel foi possível identificar as áreas com diferentes densidades de casos (casos / área), O resultado da estimativa é um mapa com diferentes tonalidades, refletindo as diferente densidades de casos observadas no período e, por conseguinte, diferentes áreas de risco.

Superpondo-se tais áreas à malha de córregos do município foram criados diferentes gradientes ("buffers") de distância e um estudo do tipo caso-controle foi realizado no sentido de se observar o risco considerando diferentes distâncias. 0 resultado foi a constatação de que o maior risco de ocorrência de Leptospirose nestas áreas compreendia os 100 metros iniciais a partir da localização do córrego. Assim, estes intervalos foram delimitados e separados segundo a subprefeitura envolvida.

Esta camada de informação foi superposta à camada dos setores censitários (IBGE, 200o), o que permitiu o cálculo dos parâmetros operacionais em cada área selecionada (número de imóveis a serem trabalhados, população abrangida e extensão dos córregos da área).
A presente iniciativa representa um avanço em termos de planejamento baseado em epidemiologia, uma vez que incorpora modernas técnicas de análise espacial na seleção de áreas de risco aumentado para ocorrência de Leptospirose, respeitando a estrutura

epidemiológica da doença e a capacidade operacional instalada.

Ao final, a somatório de todas as áreas Identificadas representou 5,6 da área do município, compreendendo 11,8 de sua população e abarcando 10,8 de seus domicílios. Da extensão total dos córregos do município, uma parcela de 9,1 encontrava-se em área de maior risco e, portando, foi selecionada para as medidas de intervenção. Nesta área relativamente pequena ocorreram cerca de 60 dos casos de leptospirose dos últimos 9 anos. 